\title{
Routines we live by: from ritual to exploration
}

\author{
Irit Lavie $^{1} \cdot$ Aya Steiner $^{1} \cdot$ Anna Sfard ${ }^{1}$ (D)
}

Published online: 1 June 2018

(C) The Author(s) 2018

\begin{abstract}
In this paper, learning is conceptualized as a process of routinization of learners' actions. We begin by operationalizing the keyword routine. Two categorizations of routines are then offered. First, we distinguish between practical and discursive routines, discuss the process of their historical co-development, and claim that over time, new discourses germinated in routines straddling different types of practical and discursive activities. Second, the distinction between process-oriented and product-oriented routines is introduced. The former type of routine is called ritual and the latter deed or exploration, depending on whether the routine is practical or discursive. The claim is made that in the process of learning mathematics, the germinal routines, from which a discourse new to the learner is to emerge, are initially implemented as rituals. In the longer run, these routines are expected to undergo gradual deritualization until they become fully fledged explorations. The question of how to identify the gradual advances in this latter process is then addressed, and this is followed by a brief discussion of the ways in which teachers may support or hinder transforming rituals into explorations. We conclude by taking a critical look at relative advantages of conceptualizing learning as the process of routinization.
\end{abstract}

Keywords Discourse $\cdot$ Routine $\cdot$ Ritual $\cdot$ Exploration $\cdot$ Task

In this paper, we put forward the thesis that repetition is the gist of learning. We claim in consequence that routines - repetition-generated patterns of our actions - can usefully replace concepts and skills as the basic unit of analysis in the study of learning. Yes, we believe that if you subscribe to a "participationist" vision of leaning as we do, the single

Anna Sfard

sfard@netvision.net.il

Irit Lavie

iritla1@gmail.com

Aya Steiner

ayasteiner@gmail.com

1 Faculty of Education, University of Haifa, 31905 Haifa, Israel 
construct of routine may suffice to let you tell useful stories about all those aspects of reality that the "acquisitionist" thinker scrutinizes through the lens of concepts and skills.

The first thing to do while deliberating on the acceptability of these claims is to look around and see that whatever we do involves routines. From the simplest, most mundane of our activities to the most abstract and sophisticated of them, we cope with the task by repeating something that we did or have seen done before. Routines both constrain and enable our functioning in the world. While ensuring reasonable stability of our ways of acting, routines are also in the process of incessant change. Moreover, as paradoxical as it sounds, routines are indispensable for innovation. They are those very things that bring novelty, often simply by being applied or combined in unconventional ways.

To understand routines, one must consider such questions as "What is it that makes a person replicate some past event?" or "How does one decide about which of the previously performed actions should now be repeated and what needs to change?" The mechanisms of repetition may differ widely from one case to another. Even if two persons have reacted to what appeared as the same situation with seemingly the same sequence of actions, at a closer inspection, the routines they performed may turn out to be different in some fundamental ways. The terms ritual and exploration, which indicate the theme of this special issue, denote different genres of routines, corresponding to different mechanisms of utilizing our past experiences. In between ritual and exploration, there is a whole spectrum of intermediate possibilities, which in the context of learning may be seen as stages in the development of a routine.

In this paper, our ambition is to lay foundations of a theory of learning as routinization. We begin with an attempt to operationalize the keyword routine. We then distinguish between practical and discursive routines. Having done this, we restrict ourselves to the learning of mathematics and introduce the distinction between two types of discursive routines: rituals and explorations. The claim is made that in initial encounters with a new discourse, the learners can only participate in this discourse in ritualized ways. In further learning, their routines are expected to undergo gradual de-ritualization until they eventually turn into full-fledged explorations. Theoretical musings on all these topics will be clarified with illustrative examples - by no means a regular research report - taken from our ongoing empirical studies. While offering all this, we will be promoting participationist stories of mathematics and its learning, told in terms of routines and of the distinction between rituals and explorations. In a concluding meta-comment, we will discuss the question of whether and how such stories can be more useful to researchers and teachers than narratives evolving around acquisitionist ideas of "concept acquisition" and "understanding."

\section{Learning as routinization}

Throughout our waking hours, we are busy performing all kinds of tasks: preparing meals, solving equations, commuting to work, playing piano, greeting friends, writing papers, chatting with colleagues, drawing, and exercising. What is it that makes us able to act the way we do? How do we know, sometimes intuitively and sometimes after some explicit reflection, that a given course of action is a proper response to the situation we are facing? At first sight, the question appears trivial: People do what they have learned to do. But what does it mean to have learned a certain way of responding to a given type of situation? 
Table 1 Two friends coming across one another

\begin{tabular}{lll}
\hline Speaker & What is said & What is done \\
\hline Gaya: & Hi Tal! How are things? & Upon seeing Tal, waves her hand, smiles \\
Tal: & Hi! I'm good. How about you? & Waves and smiles back \\
\hline
\end{tabular}

This question does not sound new or overly interesting either. Yet, taking a fresh look at what seems only too familiar and obvious can generate new insights, perhaps even help us in solving or dissolving old puzzles.

Let us begin by considering a simple example. Imagine two friends, Gaya and Tal, meeting each other. Table 1 shows how the first moments of this encounter could look like.

Why did Gaya decide that she should say something upon meeting Tal? How did she know what to say? How did Tal choose his response? The most reasonable answer is that the two recognized the situation as one in which they have been many times before- the situation of two acquaintances meeting each other-and they simply repeated what was done then. Although all this sounds trivial, at a deeper thought, this simple example does display the complexity of the idea of repetition. It is reasonable to assume that in the past, each of the two persons was privy, either as a participant or as observer, to what they now consider as precedents, that is, to situations in which two people came across one another. Not always did these people greet each other, though. Why did the present situation take the protagonists back to events of mutual greeting? Moreover, there are many ways of greeting a friend and at least as many forms in which the greeting can be answered. How did Gaya and Tal decide which of the past instances of greeting to follow?

Other complexities of repetition can be gleaned from Table 2, in which a boy by the name Milo, aged 2 years 8 months, is facing two bowls with his favorite snack called Bamba. One bowl contains five pieces and the other two. ${ }^{1}$

As before, arguably the most reasonable way to explain what happened is to say that the boy's actions were an attempt to replicate something he saw done before. If he named the quantities of pieces in the bowls, it was probably because similar utterances were made in the situations he identified as precedents. At first sight, he did what an experienced replicator would have done. And yet, Milo did not clearly make a choice of one of the bowls, the way an expert would have done. One may say that it was a mere omission or that the pointing movement was already embedded in the act of first putting down the bowl labeled "a lot." But we cannot be sure of this interpretation. In any case, the question that needs to be asked is this: After identifying a precedent, how do people decide what elements of the past event should now be repeated and what needs to be changed?

\footnotetext{
${ }^{1}$ The episode presented in Table 2 , as well as those in Tables 4, 5, 6 and 9 that follow, are taken from the first author's ongoing study of early numerical thinking (Lavie \& Sfard, 2016), in which the overall goal was to map the process of individualizing numerical discourse from its earliest stages till the moment the child goes to school. The 16 children who were chosen to participate in the study were all native Hebrew speakers from a small rural, upper middle class community in the north of Israel. The data, collected over the period of 2 years, consist of video recording and transcripts of conversations (interviews) with the children. In these ongoing one-on-one conversations, taking place every 4 to 5 months in the presence of a parent, the children are being asked to cope with situations likely to evoke quantitative, possibly numerical, discourse. To encourage de-ritualization, the same task, with only minor modifications, recur in those meetings every so often.
} 
Table 2 "Where is there more?" (Milo is 2 years and 8 months old)

Speaker What was said

76. Mother: Where is there more [pieces of] Bamba?

77. Milo:

78. Milo:
What was done

In another episode, presented in Table 3, two fourth graders, Naomi and Adi, are solving a problem shown in Fig. 1. ${ }^{2}$ Although Adi's and Naomi's actions are much more complex than those we saw in the preceding example, the mechanism behind the girls' decisions is probably similar: They clearly attempt to replicate what was done in past situations they considered as sufficiently similar to the present one to justify such repetition. One may object, saying that Naomi and Adi's actions were made possible not so much by their memory of past performances as by artifacts, such as the teacher's explicit prescription for naming points on a line or, better still, by the girls' own ability to derive the necessary procedure from what they knew about fractions. At a closer look, though, the alternative explanations are, in fact, of the same kind as the first one. Indeed, according to both of them, the performers were inspired in their actions by what was done in some past situations, except that this time, the children's memory of the precedent actions could have been more abstract - the common pattern of action they remembered might have involved actions on a symbolic artifact, such as an explicit prescription for producing a ratio of two integers corresponding to a point on a line. Whatever the nature of the present recall, Naomi and Adi had to make more decisions than Gaya, Tal, or Milo about which part of the precedent performance to replicate and which to change. In spite of the scarcity of their previous experience, the girls solved the problem as expected, and the question is what made them able to make the right choices.

Reflecting on these examples, we may say that learning is due to our ability to react to new situations by utilizing the memories they elicit. This tendency for modeling our present actions on what was done in the past results in patterns of actions that we term routines. Routinization of our actions is what learning seems to be all about. Each person develops her or his own routines, but since the source of an individual's routines is in what other, more experienced performers are doing, we all end up acting in similar, compatible ways. Indeed, we develop our routines by individualizing those that are common in our society-by turning from mere spectators of other people's routine performances into independent, agentive implementers of those routines. ${ }^{3}$ Neither the process of individualizing routines nor of applying them in new situations is automatic. More often than not, these processes require reasoned decision making, and this is true even if the reasoning is merely the backstage activity, involving only few tacit actions of recalling or choosing.

\footnotetext{
$\overline{2}$ The episode presented in Table 3, as well as those in Tables 8 and 9 that follow, are taken from the second author's ongoing study of the development of discourse on rational numbers. The design of this study is similar to the one on the early development of numerical thinking, presented in footnote 1. This time, participants, all of them from grades first to seventh, are interviewed in pairs. The process is repeated every 4-5 months over the period of 2 years. Twelve pairs of students participate in the study.

${ }^{3}$ For more elaborate definition of some of the terms introduced below it may be useful to advice the glossary of commognitive terms in Sfard (2008).
} 
Table 3 Naming a point on a number line (4th grade)

\begin{tabular}{|c|c|c|c|}
\hline & Speaker & What is said & What is done \\
\hline 1 & Naomi: & Hmm..., ok, this is zero and this is one. & $\begin{array}{l}\text { Looks at the picture, her hands under } \\
\text { the table, speaks as if to herself }\end{array}$ \\
\hline 2 & Adi: & Wait, may I..? & $\begin{array}{l}\text { Starts dividing every segment into } \\
\text { two; looks at the interviewer, who } \\
\text { nods in agreement }\end{array}$ \\
\hline 3 & Naomi: & Hmm... moment... ok. & $\begin{array}{l}\text { Looks at the picture, her hands under } \\
\text { the table, speaks as if to herself }\end{array}$ \\
\hline 4 & Adi: & And then... & $\begin{array}{l}\text { Finishes dividing the segments and } \\
\text { started counting the parts, from } \\
\text { zero on. }\end{array}$ \\
\hline 5 & Naomi: & What was I counting?! & $\begin{array}{l}\text { Straightens up, smiles and takes a } \\
\text { pencil }\end{array}$ \\
\hline 6 & Adi: & Three eights & $\begin{array}{l}\text { Raising her head from the page, she } \\
\text { looks at the interviewer and answers }\end{array}$ \\
\hline 7 & Naomi: & $\begin{array}{l}\text { Three-eighths because he is in the middle } \\
\text { of one of them... And he is in the middle } \\
\text { of the second quarter, so one needs to } \\
\text { divide into eights, because this is twice... } \\
\text { because four times two is eight... I don't } \\
\text { know how to explain this... so these are } \\
\text { eighths, so we divide, say, tick tack, tack, } \\
\text { tack, tack and he reaches three-eighths. }\end{array}$ & \\
\hline
\end{tabular}

Some may still resist the idea of learning as routinization by saying that this conceptualization does not leave space for the learner's agency and creativity. But in fact, routinization is definitely not the antonym of creativity. We readily admit that routinization does have its costs: just like any paved road reduces the traveler's motivation to venture into untrodden territories, so may familiar routines make us less likely to go in non-standard directions. Yet, we also claim that routines are those very things that bring novelty, often simply by being applied or combined in a way nobody considered so far. To see all this, suffices to consider our use of language, which is also a routinized activity: If we are able to use words, this is only because we have heard them pronounced or saw them written in the past; this, however, does not preclude combining them in sentences unlike any of those we have heard or read before. This last example also implies that our creativity may express itself not just in how we individualize and combine routines (thus creating new ones) but also, perhaps mainly, in how and when we decide to apply those patterns we already have. In short, the view according to which routinization is incompatible with creativity is not just mistaken - it is the exact opposite of what we believe true: Routines are the very stuff in which all our creativity takes its roots, the very medium in which it finds its expression.

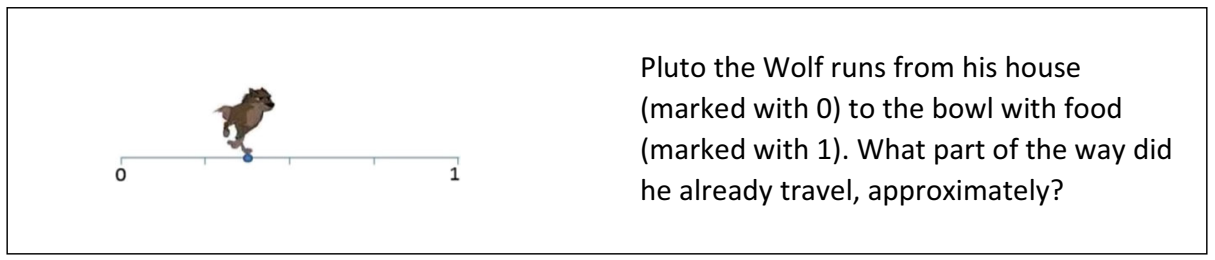

Fig. 1 The worksheet 
It is by developing routines modeled on those practiced by people around us that we turn into full-fledged members of society, capable of doing what others do, either alone or with them together. Whatever we do, we draw from our repertoire of routines. Acting collectively is made possible by the fact that we all follow similar routines and thus know how to adjust our moves to those of other players. Had we failed in our attempts to routinize our actions, our ability to communicate with others would be the first victim. It thus does not seem exaggerated to say that routinization is one of the principal conditions of humanness, and one may even see it as the most important among them.

In the view of all this, the importance of the notion of routine for the study of learning can hardly be overstated. If this notion is to become the focus of our research, it is now time to define it in terms of properties accessible to the observer.

\section{2. Operationalizing the notion of routine}

The seemingly straightforward idea of routine turns out surprisingly elusive when one tries to capture it in a proper definition. Throughout its history in research, it stubbornly dodged operationalization. In spite of this, literature on routines, while not too bulky, is impressively rich. The term routine, used as either noun or adjective, has always been present in human sciences. Used by sociologists, psychologists, and anthropologists, it is now entering educational research. This is certainly happening not only in "commognitive" literature (e.g., Sfard, 2008) but also in other places, mainly in literature on teaching (see, e.g., Horn \& Little-Warren, 2010; Khazemi, Lampert, \& Ghousseini, 2007; McClosky in this volume). Even in those cases in which researchers prefer to talk about practices or activities, the idea of routine is implicitly present. As stated by Jean Lave,

It is the routine character of activity, rich expectations generated over time about its shape, and settings designed for those activities and organized by them, that form the class of events which constitutes an object of analysis in theories of practice. (Lave, 1999, p.15; emphasis added)

For a long time, those who dealt with the subject satisfied themselves with the straightforward vision of routine as "a pre-established pattern of action which is unfolded during a performance and which may be presented or played through on other occasions" (Goffman, 1959, p. 27). Even organization theorists, who have been focusing on routines as their main objects of study for a long time now, did not, initially, see this definition as in any way problematic. This changed, though, when they realized that their attention to what remains constant throughout repetitions made them unable to account for the incessant change in human ways of acting (Feldman \& Pentland, 2003). To solve the problem, Feldman and her colleagues proposed to de-reify the notion and talk about routines as a process rather than object. "While it is still convenient grammatically to use nouns to refer to routines, theoretically we have progressed beyond routines as things," they said (Feldman et al., 2016, p. 505). Inspired by the work of Latour (1986), they distinguished between the performative aspects of routine, that is, specific instances of a routine's implementation, and ostensive aspects, that is, all those features that remain stable across different performances (in this latter case, they spoke about "enacted patterns" of 
"structure"). They then added the third, material aspects of routine: all the "actants" involved in the performance of routines, whether human or inanimate. All this, however, still did not seem to amount to a definition of routine. The question of what routine is remained unanswered.

In our research, we have been using the notion of routine for at least two decades now. During that time, its surprising resilience came to our attention from the outset, albeit for reasons different than those pointed out by Feldman and her colleagues. As explorers of learning, we could not remain oblivious to the dynamic nature of routines. After all, what is learning if not the activity of changing our ways of doing things? This said, little did we know about how extensive the relevant changes may become and how difficult it was going to be to pin down the thing that allows routine to preserve its identity throughout change. Initially, we thought about routine as a constantly evolving pattern for implementing a particular task. Each task - whether that of preparing breakfast or that of solving a quadratic equation - was supposed to have its own routine. This is, evidently, the way in which the organization scientists think about routines, since their examples of organizational routines are named after the tasks these routines are meant to accomplish. Thus, they speak, about the "academic hiring routine" applied in universities and about "hands-off routines" practiced by surgeons in operation theaters (Feldman et al., 2016). Initially, we were using a similar approach and were labeling children's mathematical routines with the names of the tasks the students were learning to perform. We spoke, for instance, about the "routine of numerical comparison." We stopped this practice, however, when it became clear that there was no reason to assume that the question asked by the researcher or teacher and interpreted by the task setter as requiring comparing cardinalities of sets would be interpreted by the child in the same way. Not only did we agree with Bruner that "at the earliest stage of inducting a child into a new activity, the adult ... [is] the only one who knows the goal of activity the two of them are engaged in" (Bruner, 1985, p. 30), but we also claimed that while facing the same situation as the adult, the child may in fact be performing a different task - a task of his own. Thus, in Table 2 above, Milo did what he did because he might have interpreted the situation as one that required choosing a bowl in whatever manner or as that of matching the bowls with quantitative labels, or both.

Having realized that we cannot speak about a task as given, we started considering routines as patterns describable with the help of two sets of rules: those that were telling the performer how to act and those that instructed her when to perform it (Sfard \& Lavie, 2005). Although for some time this solution seemed to work, after a while, we realized we had not really overcome the problem of the pervasive instability. The how and the when of the routine, just like "the task" before them, were changing all the time, turning routine into a moving target, lacking any invariant feature. If so, what was it that justified the claim that two different events may involve "the same" routine?

We felt we might have eventually pinned down the elusive concept when we decided to anchor our definition in the idea of boundary object - a perceptually accessible, material entity, constituting "a sort of arrangement that allow[s] different groups to work together without consensus" (Star, 2010, p. 602). For this purpose, we introduced the notion of task situation, meant to denote any setting in which a person considers herself bound to act - to do something. Task situation may be created purposefully by a task setter as an invitation for a certain kind of action. In Table 2, the task situation was set by the interviewer and 
included, among other things, two bowls with Bamba and the orally presented question "In which bowl are there more pieces of Bamba?" As may be clear from Table 1 (greeting a friend), however, not every task situation needs to be intentionally set. As is the case when two friends come accidentally across each other, some of such situations arise as if of themselves. As an external arrangement subject to different interpretations, a task situation can count as a boundary object.

We will now try to present a theoretical vision of the process one goes through in a task situation. From here, we hope to derive an operational definition of routine. As explained before, if a person who finds herself in a new task situation is actually able to act, it is mainly thanks to her previous experience. More specifically, she can perform because the current task situation harks back to precedents - to past situations which she interprets as sufficiently similar to the present one to justify repeating what was done then, whether it was done by herself or by another person. Sometimes, the return to a relevant past experience is a product of an explicit effort, but more often than not, it is not a matter of a conscious recall.

The process of identifying precedents would be infeasible without a certain preselection. Our search is usually restricted to a precedent-search-space (PSS, for short) arising as if of itself in a situation in which we find ourselves. A default PSS is often created before any specific task situation is set, the moment we enter a certain environment, such as a school or supermarket. This default PSS is predicated on the unarticulated assumption that precedents for whatever happens in this setting should come from the same discursive, material, institutional, and historical context. Thus, when a person enters a classroom where a mathematics lesson is about to take place, she expects that whatever task situation is going to be created during the lesson, its PSS will be composed of situations that occurred in the same classroom during the last few lessons. What happened out of school, even if likely to be deemed as relevant by an expert, would rarely be included in this school-generated PSS. ${ }^{4}$ PSS constrains our choices of precedents, and by constraining - enables them. The lack of sufficient constraints may explain why we often fail to recognize a person we know when we meet her out of the usual context. Such a meeting leaves us with a PSS too broad to be quickly scanned. On the other hand, overcoming the constraints of PSS is necessary for innovation. Most novelties are the result of crossing the PSS boundaries - of applying unusual precedents, from outside the present context.

Only some elements of the PSS will be chosen as precedents of a specific task situation. They will be found with the help of precedent identifiers, that is, according to those features of the current task situation that a person considers as sufficient to view a task situation from the past as a precedent (those characteristics that define PSS are necessary in a precedent; when then taken together with precedent identifiers, they become sufficient). Different participants faced with the same task situation may be using different precedent identifiers. Thus, for instance, the task situation in Table 2 was constructed by the interviewer with the following two task identifiers in mind: (a) the presence of two collections of counters and (b) the question "In which of them is there more?" or one that

\footnotetext{
${ }^{4}$ This may be why children often decline their parents' offers for help in mathematics homework, saying that what parents have to offer is not what their teachers do in the classroom.
} 
she considered as equivalent. As we then have shown in our analysis, Milo himself might have been guided by different identifiers in his choice of precedent task situations, and the presence of the interviewer was probably one of them.

Endowed with all these new terms, we will now revive the idea of defining routine with the help of the notions of task and procedure. Unlike previously, however, we will not speak about task in an abstract, impersonal way. The term will now be referring to $a$ person's interpretation of a given task situation. We will say that a task, as understood by a person in a given task situation, is the set of all the characteristics of the precedent events that she considers as requiring replication. By precedent event, we mean all that happened in a precedent task situation. ${ }^{5}$

Having identified the task, the person may wish to perform it by replicating the precedent action. This replication is necessarily selective: It preserves only some aspects of the past performance and changes some others. A procedure implemented by the task performer in response to a given task situation is the prescription for action that fits both the present performance and those on which it was modeled. The procedure may be deterministic (algorithmic), as it is in the case of numeric calculations or just constraining (heuristic), as is the case with most of everyday routines.

Our new definition of routine will now be grounded in thus understood notions of task and procedure. Obviously, routine will no longer be an abstract free-floating construct, but it will be tied to a particular task situation and to a particular person. We will now say that a routine performed in a given task situation by a given person is the task, as seen by the performer, together with the procedure she executed to perform the task. This said, let us immediately add that in certain contexts, we may still indicate some routines by just naming their tasks and without a reference to a particular task situation or a specific performer. Whenever we do this, as would be the case if we said "routine for a quantitative comparison of two sets," we are to be understood as referring to the routine performed by experts in task situations that they interpret as requiring canonically understood quantitative comparison.

Having defined routine as a task-procedure pair, we seem to have come full circle. We did return to the place in which we began, except for two changes. First, the task and the procedure have been disobjectified, that is, they are no longer agentless phenomena that must be the same for all participants; rather, they are somebody's vision of what is going on: They depend on the task situation and on who is doing the job of interpreting. Second, we no longer speak about routines as time independent. Instead, we introduce the notion in the context of specific performances, as one that will help us link the learner's way of acting to her previous experiences. From now, routines will be considered as being in the incessant process of becoming, as emergent phenomena that live only in the past and the

\footnotetext{
5 Two remarks on this definition are in order. First, the features of precedent events considered as those that need to be repeated define the end toward which the performer is supposed to act. This end may sometimes include not only the outcome of the precedent actions but also the actions themselves. This is the case, for instance, when the task performer feels obliged to tackle is not only to produce a certain outcome but also to produce it in a particular way. Second, different people may see different aspects of the event as its outcomes. In the case of solving equations, for instance, the student may consider the task as successfully performed if she managed to produce an expression of the form $x=$ number; another student may be looking for a number that, when substituted in the equation instead of $x$, yields a true proposition (equality).
} 
Table 4 "Where are there more?" (Milo's age 2 years, 8 months; the episode took place prior to E. 2)

\begin{tabular}{|c|c|c|c|}
\hline & Speaker & What is said & What is done \\
\hline 23. & Interv: & $\begin{array}{c}\text { And...now, where are } \\
\text { there more blocks? }\end{array}$ & $\begin{array}{l}\text { Points to two bowls, one with } 5 \text { blocks } \\
\text { and the other with } 1 \text {. }\end{array}$ \\
\hline 24. & Milo: & Here & Picks up the bowl with one block \\
\hline 25. & Milo: & One & \\
\hline
\end{tabular}

present. This said, we believe that knowing a currently enacted routine gives us good grounds for predicting the learner's future reaction to a similar task situation.

A remark should also be added on the use of the newly defined construct in empirical research. Is this construct operational enough to allow for a disciplined identification of routines in data? We claim it is, although we also readily admit that this end is not always easy to achieve. The observer's ability to raise viable conjectures about participants' interpretations of task situations is highly dependent on the amount and quality of data she has at her disposal. Let us instantiate the method with Table 2. We have previously remarked that this brief exchange was not enough to let us decide whether Milo's interpretation of the task situation was as intended by the task setter. To find a more definitive interpretation, we need some access to Milo's precedents. In our data, we were able to find several former episodes, in which a task situation was very similar to the one from Table 2. Table 4 presents one of them. The bowls this time contained blocks.

For experienced adults, the only element of precedent events that needed to be replicated in response to "Where are there more?" would have been the outcome of whatever was done to answer the question. The latter would have usually taken the form of a statement, such as "There is more in the bowl on the right." This kind of result can be attained by assessing the quantities visually, by counting, by weighting the bowls and in some other ways, but for the expert, the way does not matter-the actual actions of performers are usually not among the required common features of all the precedent events. For Milo, it seems, the situation was different. The child's performances in Tables 2 and 4 did display many commonalities. For instance, in both cases, he matched the bowls with quantitative labels. In both cases, he marked in one way or another one of the bowls or both of them. We conclude that for the child, the task was probably to repeat - to the best of his understanding - the actions performed by adults in precedent events. There was no final outcome to speak about, only a "halting signal" (a situation to be interpreted as a sign that the procedure has been completed). Thus, based on his two performances in seemingly equivalent task situations, our conjecture is that the two parts of Milo's routine, the task and the procedure, were in fact indistinguishable: For him, repeating the whole performance was the task. This conclusion will remain a conjecture, but a scrutiny of additional potential precedents may either add to its plausibility or lead to its refinement or change.

Let us end this section with a number of more general remarks. First, we must always remember that identifying routines is an interpretive activity for the performer and the observer alike. Second, whatever the observer's interpretive method, looking at just one isolated episode is not enough. The greater our access to the history of one's action, the more robust our claims on this person's evolving routines become. Third, if learning is a process of gradual routinization of our actions, investigating learning is tantamount to answering the question of how routines emerge and how they later evolve. Finally, although all our examples presented 
routine performances of specific persons, routine is a unit of analysis for investigating learning not just of individuals, but also of collectives, and thus for studying both ontogenetic and historical developments. The rest of this paper is devoted to these latter issues.

\section{3. Historical growth: co-development of practical and discursive routines}

Routines we develop improve our ability to respond effectively to our needs, and thus, routinization of our actions can be seen as one of humans' basic survival techniques. It is reasonable to assume that at least historically, the emergence of routines was prompted by our existential needs, such as getting food or ensuring physical security. Since humans are also predisposed to collaborate (Tomasello, 2014), there was another type of need that had to be taken care of in parallel - the need for communication. Accordingly, there are two types of routines that emerged and evolved along history, practical and discursive. Ever since its inception, each such routine has been subject to individualization by new members of the culture within which it was practiced. Below, we argue that at least historically, practical and discursive routines have been spurring each other's development. But first, let us clarify the basic distinctions.

We describe a routine as practical if a person interprets the task situation as requiring a change, re-organization or re-positioning of objects. Routine physical actions such as biking or swimming, and such everyday activities as preparing breakfast, dressing or cleaning one's teeth are good examples. We describe a routine as discursive if a person interprets the task situation as requiring a communicational action. In other words, discursive routines are patterns we follow while communicating with others or with ourselves (routine-as-a-patternof-action remains a useful first approximation of our refined definition). All the routines exemplified in Tables 1, 2, 3, and 4 can thus be classified as "discursive." Indeed, although some of these vignettes did mention changes in the physical environment (for instance, in Table 2, the two bowls were repositioned, and in Table 3, the participants made marks on paper), these changes served the communicative process. Note also that it is not the performance as such but rather the desired outcome of the performance - the expected change in objects or relations in objects or the fact that something has been communicated - that makes a routine into practical or discursive. Some practical routines are performed discursively rather than in the form of a physical action, and the act of wedding, which changes the relation between people, is a good example. Finally, some routines can thus be considered as practical in one context and as discursive in another.

The word discourse itself denotes a particular type of communication, distinguishable from any other by its keywords and the ways they are used, by the perceptually accessible aspects of material reality that are being employed as "helpers" (we call them visual mediators), and yes, its routines. With the help of this discursive apparatus, participants of the given discourse communicate with one another and tell narratives about chosen aspects of reality. School is a place for fostering different types of historically established discourses, such as biology, in which stories are told about living creatures; history, the discourse that produces accounts of past generations; or mathematics, where the protagonists of the narratives are abstract mathematical objects. It is important to stress that discourses are multimodal, that is, although communication is often carried out in words, there are other means as well—gestures, concrete objects, pictures, and many more. Verbal language is neither an exclusive nor indispensable means of communication. Nor must the 
use of a given discourse be interpersonal. Indeed, a person can have a lengthy episode of communicating with herself mathematically while trying to solve a problem. The common word for such self-communication is thinking.

Endowed with this definition of discourse, we can now substantiate the claim that throughout history, practical and discursive routines have been spurring each other's development. For example, the development of the routine of counting, which can well be considered as the "germ" from which numerical discourse would develop later on, might well have emerged when our ancestors attempted to extend their practical routine of choosing the largest of available sets of things. Our distant predecessors, just as the majority of today's children, were likely capable of such qualitative choices long before the quantities could be labeled with numbers (Sfard, 2015). In the absence of numbers, however, these comparisons could be made only if the sets were simultaneously present and close to one another, so that their elements could be arranged in a direct one-to-one correspondence. In other situations, a person might try to use an auxiliary set, say of her own fingers, that could be compared to each of the original sets separately. With the invention of the routine of counting, such mediating sets could be replaced with a much more effective devises: numbers. Given this hypothetical historical account, it is justified to say that the practical routine of choosing sets stimulated the emergence of the discursive routine of counting. This latter story could be continued to explain how the subsequent wish to extend the practical routine of choosing to one that could be performed on continuous objects spurred the emergence of new numerical routines. By pairing natural numbers in particular ways people could then make choices according to dimensions such as length, area, volume, or weight (Lavie \& Sfard, 2016; Sfard, 2015). These successive extensions were likely to lead to the emergence of discursive routines involving pairs of natural numbers called ratios, and in the longer run, to the formation of the fully fledged discourse of rational numbers.

More generally, the history of most, if not all, of the existing mathematical discourses may be shown to be going back to a certain collection of discursive routines, to be called here discourse-germinating or simply germinal, that evolved throughout attempts to refine a certain practical activity. The new discourse started emerging when people realized that a number of routines displayed the same pattern, even though so far they did not appear to have anything in common. Thus, consider routine activities such as

Preparing three portions of soup from a recipe for eight portions.

From the provision of pencils meant to be shared equally by two teams of three and five people, respectively, separating a portion that should be given to the team of three.

While planning an 8-day-long journey to be made in equal daily segments, finding the location at which the traveler will find herself at the end of the third day.

All three of these activities may be described as geared toward the task of finding three eighths from a certain whole. This common description was enabled by the introduction of the new noun, three-eighths, that within each of the practical routines listed above could be interpreted as a particular concrete object: a serving of food, a set of pencils, a location on a route. All these concrete objects might now be said to constitute realizations of the new signifier "three eighths"; the signifier itself, together with all its possible realizations, could be viewed as a new mathematical object, later realizable also in a symbolic form as the fraction $3 / 8$. 
This last example shows two typical occurrences in the historical emergence of new mathematical discourses: first, introduction of a new mathematical signifier that would eventually lead to the formation of a new mathematical object, and second, using the new signifier to link some germinal routines into a single one through a common description of their tasks. The procedure of such consolidated routine splits up into a number of alternative branches, each of which is taken from one of the constituting germinal routines. Thus, as the historical development continued, the germinal routines were gradually turning from standalone forms of activity into elements of an intricate, tightly interwoven network. In the next section, in which we look at ontogenesis of mathematical routines, we will see how a similar interweaving may be happening at a more individual level.

\section{4. Ontogenesis of mathematical routines: transforming germinal rituals into explorations}

Though it is reasonable to expect some parallels between the historical and ontogenetic development of discursive routines, it is just as justified to expect differences. After all, new discursive patterns do not enter individual lives in the same way in which they appeared in the course of history. Rather than being brought into being by some practical, genuinely felt need, new discursive routines may appear uninvited, presenting themselves to the learner as readymade patterns of communicating, widely practiced in the society into which this learner was born. All this is true even if teachers follow the current pedagogical recommendations and evoke new discursive routines "within familiar everyday context." Indeed, no problem posed by the teacher, be it as practical and familiar as it may, reflects children's currently felt needs. Hence, the solvers cannot be guided by their own genuine interest in the outcome.

When a child begins developing a new numerical routine, she cannot possibly be motivated in her actions by her appreciation of its usefulness. In this early stage, she cannot yet know how the routine can help in solving real-life problems. The child's readiness to address task situations set by others can thus be explained only by her wish to be like everybody else and do whatever other people are doing. In our case, this would mean the processes of individualization of all three routines exemplified in Tables 1, 2, and 3-that of greeting an acquaintance, of comparing sets and of naming a point on the line - were set in motion not so much by the children's own physical, emotional, or cognitive needs as by their yearning for social acceptance. Let us take a closer look at Milo's case. What we saw in Tables 2 and 4 may be described as one of the first steps in his attempts to individualize the routine of numerical comparison, as this routine was probably demonstrated to him by people more adept in discursive practices than himself. Because of the paucity of the child's previous experience, it was not surprising that what he actually did was quite different from what any adult would have done. For the expert, the task would have been to arrive at a certain narrative about the two sets. For the child, however, such a narrative would be of no use even if he knew how to create it. At this point in the process of learning, he is not yet aware of its practical implications. The future uses could therefore not be the goal of his activity. Instead, we assume that Milo was trying to do what others were doing, and his actions were focused on the process as such. It thus seems appropriate to call the outcome-oriented routine of the expert exploration, and the process-oriented performance of the child - ritual. Similar distinction can be made for practical routines, except that this time, the term deed appears more suitable for 
the outcome-oriented routine (see Table 5), because in this case, the expected outcome comes in the form of new, transformed or rearranged objects.

In simpler terms, an explorative task is to yield a new "historical fact," a new "truth" about mathematical objects, etc. This is the only requirement, and there is no specification with regard to the way in which this work is to be done. Adding two numbers, say 351 and 28, is an exploration if the implementer thinks about the task as one of constructing and endorsing a new narrative about mathematical objects (which, in this case, would be " $351+28=379$ "). But adding may be also a deed, and this is the case if in the eyes of the person, 351 and 28 are objects and she considers as her task combining them into a new one (379). Both deeds and explorations may be seen as acts of production: Their execution is judged exclusively by the artifacts they generate. In the case of a ritual, where the task and the procedure are one, the performers do not ask themselves "What is it that I want to get?," as do those involved in deeds and explorations. This time, "How do I proceed?" is the only question that guides their actions. Since the resulting performance does not count as an act of production, one can only have social reasons for a ritual activity. Indeed, we perform rituals when we feel expected by others to do so, and in particular, when the expectation comes from those whom we see as in any way superior to ourselves. Thus, one can say that rituals are routines performed for the sake of social rewards or in an attempt to avoid a punishment.

It is because of this latter characteristic of the ritual that we decided to borrow its name from anthropologists and sociologists, in whose languages it features most prominently. Ritual is one of the key notions in studies on cultural habits (Etzioni \& Bloom, 2004), on interactional patterns (Goffman, 1967), and on religious rites and ceremonies (Bell, 2009). Human scientists' current interest in rituals is due mainly to the work of Catherine Bell (2009), who revolutionized the approach to the topic while claiming the central role of this special form of social action in the functioning of human society. To put it in the words of Jonte-Pace (2009), ever since Bell's groundbreaking insights, "ritual, long understood as thoughtless action stripped of context, is more interestingly understood as strategy: a culturally strategic way of acting in the world" (p. vii). More recently, the notion of ritual was also found useful in organizational sciences (Insper \& Zyphur, 2009). According to sociologists, rituals "reinforce the traditional social ties between individuals" (Geertz, 1973, p. 142) and impose meaning on seemingly chaotic and arbitrary experience. In itself, "[r]itual is pure activity, without meaning or goal” (Staal, 1975, p. 9). Our definition of ritual as a fully process-oriented routine, appreciated for its performance and not for its product, seems to echo this latter description.

In mathematics classrooms, pure rituals or sheer explorations are rare occurrences. According to our definitions, it is now possible to speak about a continuum of forms, differing one from another in the performer's ability to separate the procedure and the task, and thus, there is a full range of possibilities, for which ritual, on the one hand, and deed and exploration, on the other, are just extreme cases. As long as a specific procedure remains a part of the taskthe performer does not just strive to arrive at a particular outcome, but also feels that a specific procedure must be used for this purpose - the routine cannot count as a full-fledged exploration.

Table 5 Types of routines

\begin{tabular}{lll}
\hline Routine & Process-oriented & Product-oriented \\
\hline Practical & Ritual & Deed \\
Discursive & Ritual & Exploration \\
\hline
\end{tabular}


It is the explorative mathematics, we wish to believe, that the majority of mathematics teachers want their students to develop. Indeed, rituals are often disparaged as mere attempts "to please the teacher." This said, rituals are a necessary occurrence in the process of individualization and thus cannot be banned from the classroom altogether. In the case of germinal routines - those routines from which new discourses are likely to develop - there is no other way to begin the process of individualizing than by adopting it as a ritual. Indeed, to recognize the outcome of such routine as the exclusive aim of the performance, the child would have to be aware of some practical application of this outcome. But how could she develop such an awareness before having some experience with the routine? The situation is particularly problematic if the assignment for which the routine is to be crafted has been presented in the language of mathematical objects the child encountered now for the first time. These objects, too, could not have been constructed without the germinal routines that are now in the process of being developed! All this shows that rituals constitute stepping stones for new discourses and, as such, are an inevitable presence in mathematics classroom.

Some routines in which we are all adept are destined to stay rituals forever. Such is the case for the greeting routine, which is socially oriented by definition and whose goals are achieved by its very performance. The situation is different for mathematical routines, which to be truly useful must evolve into full-fledged explorations. We know from previous research that the process of de-ritualization - of transforming ritual into exploration - may be gradual and slow (Sfard \& Lavie, 2005; Lavie \& Sfard, 2016), and only too often will not be completed in school (Sfard, 2017). To map this process, one must observe the learner over time and document as many of his performances in a given type of task situation as possible. Later, while analyzing the records, the researcher needs to decide how each of these performances differs from its predecessors.

According to our definitions, an observed change in the performance will count as a step in the de-ritualization of the respective routine only if it indicates that the performer's attention shifted from the performance as such to its outcome. Below is a partial list of changes that can be interpreted as showing such a shift. In all these cases, the change expressed itself in the strengthening of one or more of the desirable characteristics of routine: flexibility, bondedness, applicability, performer's agentivity, objectification of the discourse, and substantiability. We illustrate some of the changes with examples coming from our diverse research studies.

Flexibility The rise in the flexibility of a routine means that there is now more than one way to perform the task. In this case, the procedure can be said to have branched into several alternative paths. This happens when the child realizes that other, hitherto unrelated, procedures can be used to perform the same task. A change such as this is clearly a move toward exploration, since the newly enabled variation in the performance means that the outcome came to the fore as the repetition-requiring common element of the precedent events.

It was 13 months after the episodes presented in Tables 2 and 4 took place that we saw the first signs of such flexibility in Milo's routine for answering the question of "In which bowl are there more blocks?" In Table 6, after assessing visually the relation between the piles of five and three blocks, the child explains yet another method. 
Table 6 "Where is there more?" with regard to piles of five and three blocks (Milo's age 3 years, 9 months)

\begin{tabular}{|c|c|c|c|}
\hline & Speaker & What was said & What was done \\
\hline 69 & Interv: & $\begin{array}{l}\text { And how do you know that in the } \\
\text { purple pile there are more blocks? }\end{array}$ & $\begin{array}{l}\text { Places in front of her } 5 \text { purple blocks and } \\
3 \text { brown blocks (Milo had just pointed } \\
\text { at the larger pile (of } 5 \text { blocks) }\end{array}$ \\
\hline 70 & Milo: & Because I put it for myself. & Playing with the larger pile ( 5 blocks) \\
\hline 71 & Interv: & Because you put it for yourself? & \\
\hline 72 & Milo: & Yes. & \\
\hline 73 & Interv: & What did you put? & \\
\hline 74 & Milo: & If we build this, we will see that it is not tall. & $\begin{array}{l}\text { Puts the brown blocks one on top of } \\
\text { another and builds a tower. }\end{array}$ \\
\hline 75 & Milo: & And if we build this, we will see that it is tall. & $\begin{array}{l}\text { Referring to the purple blocks. Puts the } \\
\text { purple blocks one on top of another } \\
\text { and builds a tower. }\end{array}$ \\
\hline 76 & Interv: & Great, great. Well done. & \\
\hline
\end{tabular}

As can be seen, Milo's routine now offers two alternative performance paths: The child can respond to the question by comparing the piles visually or by aligning towers into which the blocks have been arranged. He is clearly aware that the two procedures need to produce the same outcome.

Bondedness Using a metaphor taken from chemistry, we call routine "bonded" if the output of any given step in its procedure, if not yet the desired final product, feeds in (is used as an input) in latter steps. This is clearly a necessary characteristic of an exploration, in which every move is geared toward a certain final outcome, and there is thus no space for redundancies - for steps that are not bonded to others. When the child starts imitating another person's performance, she may be unaware of the relation between successive steps and although she may try to replicate them all, she is unlikely to actually bond them by using an output of one as the input for the next. This is exemplified by Milo's pretend counting in the episode presented in Table 7 that took place 8 months after the episodes in Tables 2 and 4 and 5 months before the episode from Table 6 (see turns 12 and 13b).

It took another 8 months before we could say with full certainty that Milo's counting became relevant to his subsequent decision about which of the sets should be chosen in

Table 7 "Where is there more?" with respect to the piles of five and three blocks (Milo's age 3 years, 4 months)

\begin{tabular}{|c|c|c|c|}
\hline & Speaker & Said & Done \\
\hline 6 & Interv: & And now, which pile do you choose? & \\
\hline 7 & Milo: & This one & Puts his hand on the larger pile. \\
\hline 11 & Interv: & $\begin{array}{l}\text { And in which pile are there } \\
\text { more blocks? }\end{array}$ & \\
\hline 12 & Milo: & & $\begin{array}{l}\text { Points his finger at the larger pile (5) and } \\
\text { touches two blocks, as if counting. }\end{array}$ \\
\hline $13 \mathrm{a}$ & Interv: & $\begin{array}{l}\text { In which pile is there a larger } \\
\text { number of blocks? }\end{array}$ & \\
\hline $13 b$ & Milo: & & $\begin{array}{l}\text { Touches the larger pile with his finger, as if in } \\
\text { the process of counting; does not keep 1-to- } 1 \\
\text { correspondence }\end{array}$ \\
\hline
\end{tabular}


response to the question "Where is there more?" Turning again to a metaphor from chemistry, we can say that before the bonding happened, his routine was a loose mixture of steps, and when it occurred, the routine changed into a compound. This kind of change is a sign of further de-ritualization.

Applicability We speak about a routine's applicability while considering the range of task situations for which its performances so far are likely to constitute precedents. For rituals, this space of potential future applications is extremely limited: Since the ritual is practiced not for its self-sustained product but as a way of spending time within particular human and physical environment, it can be evoked only if this environment is reproduced in almost all its details. The performance of a ritual is a self-sustained event, one that does not feed its outcome into people's subsequent actions-or into other routines - in any genuine way. The ritualized nature of Naomi and Adi's routine of naming a point on a number line (see Table 3) was brought to our attention in later task situations, in which the girls could have used this routine, but did not do so. This is instantiated in the episode in Table 8 that took place several months after the one presented in Table 3, when the participants were already in the fifth grade (to remind, in the episode in Table 3, they were still fourth graders).

This time, the girls were given almost identical drawings of the number line, except that in Adi's copy, there was a dot on the line, which Naomi was expected to reproduce by following Adi's verbal guidance over the phone. Using her demonstrated ability to name the point with a fractional number $\left(2^{3} / 4\right.$, in this case) would have helped Adi in this assignment, and it would have been useful for Naomi too, since she has already shown at another occasion her ability to translate a fraction into a number line location. And yet, none of these fraction-involving routines was applied, and as already stated, we take this fact as an evidence of the routines' ritualized character.

Naomi and Adi were asked to perform the telephone assignment over and over again during the following months, but although their procedure underwent several refinements, it did not involve point-naming and point-reading. It was only 18 months after the episode in Table 8 took place that the girls evoked that routine in that context, as shown in Table 9.

Here, Adi began by naming the point to be copied with a fractional number (see the "two and three quarters" in turn 5). Later, her partner used the point-reading routine while

Table 8 Adi instructs Naomi by phone how to reproduce a point on a number line (fifth grade)

\begin{tabular}{|c|c|c|c|}
\hline & Speaker & What is said & What is done \\
\hline 1 & Adi & $\begin{array}{l}\text { [Put it] between two and three. Measure } \\
\text { with your pinky turned to the side. } \\
\text { This is the space between three and } \\
\text { the circle. }\end{array}$ & $\begin{array}{l}\text { By "three," she means the point on number } \\
\text { line marked with } 3 \text {. By "the little circle," } \\
\text { she means a sign used to mark the } \\
\text { required location on the line. }\end{array}$ \\
\hline 2 & Naomi & Approximately.... & $\begin{array}{l}\text { Puts her pinky orthogonally to the number } \\
\text { line immediately next to the point marked } \\
\text { with } 3 \text { and marks the location with a } \\
\text { little circle. Then, she compares her } \\
\text { drawing to Adi's original and appears } \\
\text { dissatisfied. Tries to measure the distance } \\
\text { from } 3 \text { with her pinky again }\end{array}$ \\
\hline 3 & Adi & [Turn your pinky] to the side, to the side... & \\
\hline
\end{tabular}


Table 9 Adi (sixth grade) instructs Naomi "by phone" how to reproduce a point on a number line

\begin{tabular}{|c|c|c|c|}
\hline & Speaker & What is said & What is done \\
\hline 1 & Adi & Ok, divide between 2 and 3 into quarters & $\begin{array}{l}\text { Looks at the page and marks with a finger } \\
\text { the division of the interval between } 2 \text { and } 3 .\end{array}$ \\
\hline 2 & Naomi & Ok... three quarters? & Looks at her page \\
\hline 3 & Adi & Yes & Looks at her page and smiles \\
\hline \multirow[t]{2}{*}{4} & both & & laugh \\
\hline & Naomi & & $\begin{array}{l}\text { Divides the interval between } 2 \text { and } 3 \text { into } \\
\text { four more-or-less equal parts }\end{array}$ \\
\hline 5 & Adi & $\begin{array}{l}\text { Perfect. So two and three quarters, } \\
\text { approximately. }\end{array}$ & Looks at her page \\
\hline 6 & Naomi & $\begin{array}{l}\text { Approximately. I'm not good in doing } \\
\text { things precisely }\end{array}$ & $\begin{array}{l}\text { Draws the little circle. Straightens up while } \\
\text { saying "approximately" }\end{array}$ \\
\hline
\end{tabular}

reproducing the desired location on the line. ${ }^{6}$ We can summarize by saying that in episode in Table 9, a breaching occurred in the hitherto impermeable wall that kept the school-learned point-naming and point-reading routines inaccessible to out-of-school uses. We consider this finding as indicating a decisive progress in de-ritualization of these routines.

Performer's agentivity In ritual, where the exact performance of a procedure constitutes the task, the performer is not free to decide what should be done and when. In this, she is totally dependent on other people. The presence of another person, either actual or just imagined, is necessary in every phase of the ritual performance: to initiate the execution, to make decisions necessary to proceed, to know when to continue and when to stop, and to evaluate the action. One can say that the learner executes rituals vicariously, on behalf of other people.

Since the branching of a procedure is one of the typical changes that happen in the process of transforming ritual into exploration (see under "bonding" above), de-ritualization expresses itself, among others, in a growing number of decisions the learner is able to make without being helped by another person. Stretches of her uninterrupted independent activity become longer. The ultimate sign that one's routine has become a full-fledged exploration is that the performer does not need another person's invitation to engage in the performance of the routine: She is now capable of setting the relevant task situations for herself, in response to her own needs.

Objectification When we recall a precedent event, it is the implicit story we tell ourselves about this past situation rather than the situation as such that is remembered. As time goes by and one's experience with the given routine grows, the story becomes more and more abstract, that is, it starts being told as a narrative on mathematical rather than concrete objects. In the end, it is remembered as performed on, say, integers or rational numbers rather than on the concrete things that serve as their realizations (bowls with blocks or snacks, parts of things). As explained before, these abstract objects are introduced to unify hitherto unrelated routines and

\footnotetext{
${ }^{6}$ If Naomi could actually guess the number before getting exact instruction from Adi (turn 2), it was probably because she had several earlier experiences with exactly the same assignment and could recall the image of the line with the point. She was now able to name this point also without her friend's guidance, and this is probably the reason why both girls giggled (3).
} 
Table 10 Milo reacts to the question "How do you know?" in the end of Table 7 (age 3 years, 4 months)

\begin{tabular}{llll}
\hline & Speaker & Said & Done \\
\hline 14a & Interv: & $\begin{array}{c}\text { And in which pile is there a smaller } \\
\text { number of blocks? }\end{array}$ & $\begin{array}{c}\text { Touches the smaller pile with his } \\
\text { finger, as if counting }\end{array}$ \\
$14 \mathrm{~b}$ & Milo: & & \\
15 & Interv: & How do you know? & Ah..ah..ah.. because I was once in your place \\
\hline
\end{tabular}

to account for the equivalence of their procedures. Once the abstract entity is satisfactorily formed, a person faced with a task situation involving this object does not have to go back to precedent task situations that involved concrete objects; instead, she may now derive the necessary procedure from the properties of the mathematical object. After all, these objects are reifications of known procedures and can thus be regarded as condensed precedent sets. Objectification of the language used by the learner - the student's greater tendency for using nouns - is thus yet another indication of the progress of de-ritualization.

Substantiability As long as her attention is given exclusively to the process, the performer has no criteria by which to assess her own performance and must rely in this respect on the judgment of those whom she regards as authority. The way she responds to the request for a substantiation of what she did may thus provide additional clues about the state of the routine. An example that brings more evidence for the ritualized nature of Milo's performance in Table 7 can be found in Table 10, which constitutes its direct continuation:

Here, after answering the query about bowls with blocks (14a, 14b), Milo responds to the question "How do you know?" (15) by saying "Because I was once in your place" (16) (the words "your place" evidently refer to the laboratory where the interviews were conducted). In this answer, he refers to a past situation that served him as a precedent. This response, in addition to confirming Milo's focus on the process - he knew what to do because he has already seen it done - stresses the role of recall and precedents in Milo's attempts to react to task situations.

Many children respond to the request for substantiation by simply describing the process they just performed. Thus, a student presented with an equation would often argue for the acceptability of her subsequent actions by recapitulating these actions and showing that they were performed correctly. Like in the previous case, this response suggests the ritualized nature of the routine. This changes once the student starts responding by showing that the number she got, when substituted instead of the unknown in the equation, yields a numerical equality. In this case, the observer can claim a considerable shift of the performer's attention from process to outcome and thus from a ritual to exploration. ${ }^{7}$ The same can be said if the learner does what Milo did in Table 6: substantiates his performance by showing that an alternative procedure would have yielded the same outcome.

We could list many other properties of performances that change in the process of deritualization. In spite of the diversity of possible indices and of the multiplicity of ways in which they can be studied, the process of turning rituals into full-fledged explorations is not easy to follow. The elusiveness of the relevant features and the need for a careful study of rich longitudinal data make the task quite demanding for the researcher. For the teacher, who must observe

\footnotetext{
${ }^{7}$ In some cases, though, also the act of substituting the solution back in the equation may be learned as a ritual. The observer needs more evidence to be able to claim that the substitution has been performed out of the performer's genuine need to assess the success of the former performance.
} 
performances of many students simultaneously and for whom these performances are transitory events, it may appear almost undoable. This is one of the reasons why helping students in transforming initial rituals into explorations is among the principal challenges in teaching mathematics. Another, not any less serious factor to consider in this context has to do with the institutional setting of learning. School, by the very nature of its mission, seems destined to cultivate rituals. In the classroom, the student can learn a procedure, but since school is not a supermarket, home, or workplace, the learner is unlikely to create precedents for out-of-school uses of these procedures. Theorizing on such uses can help, but only to some extent. No wonder, then, that all parties involved, mathematics students and teachers alike, tend to view the learning of procedures as their mission. Rituals will develop in every classroom, whether the teacher likes it or not. In contrast, whether these routines will preserve their ritualized character forever does depend on the teacher. As shown in previous research (e.g., Sfard, 2017), even well-meaning teachers may sometimes inadvertently collaborate in perpetuating rituals. The teacher's own mathematical discourse is the model for the learners to follow, and the question is whether its explorative nature gets through to the students clearly enough. The teacher must remember that a conscious effort on her part may be necessary to make it visible.

\section{5. Closing meta-reflection: some benefits of thinking about learning as routinization}

Underlying our decision to devote this paper to the notion of routine was our belief that conceptualizing learning as a process of routinization may generate new insights. Below, we argue that this approach may, indeed, help in dealing with some resilient quandaries that have been stymieing learning scientists for as long as they remember.

Bridging individual and societal learning conceptually Routines emerged from our deliberations as the basic building blocks of all our activities, whether practical or discursive. This is quite a change, since so far, it was the construct of concept that has been playing this role in research on learning. In the eyes of both acquisitionist researchers inspired by Piaget and participationist who follow Vygotsky $(1978,1987)$, expressions such as, say, the development of numerical thinking is tantamount to the formation of the concept or number. In our studies, it is the discourse in its entirety that constitutes the object of research, whereas routine is the unit of analysis - the smallest manifestation of the discourse considered in analyses.

An important advantage of this unit is that it is defined operationally. Unlike the notion of concept, the idea of routine has been described in terms of features accessible to the observer, at least in principle. Its other important merit is that as a pattern of activity, routine is observable on both individual and societal levels. At the first of these levels, routines are detectable in the actions of a particular person over time, and at the second - in the ways of acting that are widespread in a given society. Having a common unit of analysis for these two levels of the complex system called "human species" makes it clear that individual learning and historical development feed into each another (Sfard, 2008). Endowed with such a multifaceted conceptual basis, learning scientists may now be on their way to deeper insights about the mechanisms of changes on both individual and societal levels. In result, the oft quoted claim about the social nature of learning, acquires new meaning: Since learning means making one's actions patterned in ways similar to those that are visible in the society as a whole, we may now claim that learning turns the learner into a micro-society in its own right. 
Escaping the pitfalls of the talk on understanding In this paper, we offered the possibility to bypass the need for the word understanding while talking about mathematics learning. We attained this effect by describing the mathematical performance of a person or community using the words ritual and exploration, and these two adjectives demarcate a whole range of options, which would likely be described in traditional language as "various levels of understanding." Needless to say, we did not introduce this change just to say the same thing in different words. Something important is to be gained from the possibility to bypass the talk on understanding. This gain will be explained in a moment, but not before we present our reasons for wanting the change.

Why should one want to demote the word understanding from its place of honor in educational researchers' discourses? A number of arguments have been presented elsewhere (Sfard, 2008), but we will now satisfy ourselves with noting the insurmountable ambiguity of the term. As eloquently argued by Wittgenstein (1953), one's private experience is uninvestigable, that is, one cannot capture it in propositions, the correctness of which could then be reasonably judged by other people. And indeed, mismatches between people's first-person and third-person stories about their understanding, or even between two statements of different assessors on one individual's understanding, are a common occurrence. The word understanding, therefore, escapes operational definition, and when used, it blurs more than it clarifies. As such, it is practically useless for the researcher who wants her stories of learning to be truly helpful to practitioners. Indeed, what is the use of advice that can be interpreted by a person any way she wants?

The main benefit of the transition from the talk on understanding to that on rituals and explorations is that while focusing on properties of one's actions rather than making an attempt to say something "objective" about her inner experience, we transfer the debate to the public arena, where our private worlds are collectively shaped. While scrutinizing the interpersonal occurrences, we begin realizing that the inner experiences, rather than being the primary factor that molds our actions, are, to great extent, a product of the ways in which we interact with others.

It is important to stress that the replacement of the talk about understanding with one about rituals and explorations does not imply we deny the experience of understanding. Indeed, we are not behaviorists. On the contrary, we are always mindful of the omnipresence and importance of the experiences due to which people make occasional remarks on their own and other persons' understanding. While observing and analyzing processes of learning we do keep in mind that what is happening covertly inside a person is of utmost significance to what is overtly happening between people. This awareness, however, does not translate into an attempt to do the impossible - to actually reconstruct the experiences that underlie the processes we observe. This is why the word understanding does not feature in our research vocabulary (we do use this word while quoting the participants of our studies, though).

Escaping the pitfall of the talk of deficit One of the salient features of the routine, stressed by our definition of this construct, is the fluidity of all its ingredients. We are always mindful of the fact that when a routine develops, two elements evolve, not just one: In addition to the ever-changing procedure, which until recently seemed to constitute exclusive focus of those who investigated routines, ${ }^{8}$ we study the learner's interpretation of a task situation, which we see as not any more stable than the performer's actions. Attending to the change in task

\footnotetext{
${ }^{8}$ Although most researchers do recognize the fact that children may sometimes interpret a task differently than intended by the task setter, they rarely act on this insight. More specifically, they do not take the difference in participants' interpretation of task situations as the default tenet of their research and do not attempt to reconstruct these differing interpretations as a standard, necessary part of their studies.
} 
protects us from falling into the trap of the "deficit model" - of reporting only on what the child "did not do," while remaining silent about what and why he actually did. We now know that saying "Milo did not use counting to compare sets quantitatively" would be misleading, because comparing sets quantitatively did not appear to be the task Milo was trying to accomplish. Having lifted the veil of our own interpretations of the world, we got a glimpse of the colorful paths children pave for themselves through unknown territories before they reach the well-trodden routes of the grownups.

Reconceptualizing situativity of learning Situativity is the name given by researchers at the end of the previous millennium to people's widely observed inability to help themselves with routines learned in school while solving real-life problems (Brown et al., 1989; Greeno, 1997; Lave, 1988). Those who introduced the term complained about the fact that this widespread failure remained unaccounted for by the existing theories of learning. They ascribed this lacuna to the learning scientists' use of inadequate metaphors: Traditionally, learning was conceptualized as an "acquisition of knowledge," with knowledge itself "conceived as a set of tools stored in memory, carried around by individuals" (Lave, 1988, p. 24). This latter metaphor had its most salient expression in the concept of transfer, for the existence of which the evidence was scarce, if any. We now wish to claim that thinking about learning as routinization of people's actions protects us against the pitfalls of acquisitionism (Sfard, 1998) and gives us a deeper insight into the phenomenon of situativity.

Within the proposed framework, situativity of learning is nothing else than insufficient deritualization. As long as one's routine is a ritual, and is thus identifiable by its procedure rather than by outcome, these are situational affordances for the performance that serve the performer as precedent identifiers. For instance, the presence of people with whom the routine was previously performed and the availability of the concrete objects with which the procedure was carried out may be necessary conditions for the new enactment of the procedure. Aware that many of the routines taught in school are learned as rituals, we should not be surprised that the evidence for the "transfer of learning" is scarce, at best.

What can be done about it? According to the theory, rituals and thus situativity, are inevitable in the initial stages of learning about new mathematical objects. If they last, however, and fail to turn into explorations, one can say that school did not live up to its commitment. On the other hand, there are at least two factors that make it difficult for school to be fully successful in overcoming ritualization. Both of these factors have already been mentioned in passing, but they are serious and important enough to deserve additional attention. First, task situations created in school are not predisposed to serve as precedents for out-of-school situations, and this is true even if their designers have toiled to "put mathematics in real-life context." People, it seems, live in the world partitioned into almost non-intersecting precedent-search-spaces, and the boundaries of these spaces coincide with those of discourses and institutions. This means that a person faced with a problem at home or in a supermarket will, by default, search for suitable routines among past situations she encountered within the same context. In school, one's searches for precedents are unlikely to exceed the boundaries of school mathematical discourse. The walls of the classroom, it seems, separate discourses impermeably. Second, ritualization is as-if inscribed in the mission of school: The mathematics teacher aims at equipping students with procedures that are generally considered as potentially useful in a wide variety of situations. It is thus the way students perform numerical calculation, solve equations, prove theorems, or explore functions that the teacher is trying to monitor most closely. In result, the student, when presented with a request such as "Solve the equation" or 
"Prove that this property holds for any natural number," considers herself as assessed according to her mastery of the procedures that have been taught. Even when encouraged to solve an equation "in any way she wishes," the learner would rarely dare to use the method of trial and error, and when asked to prove a theorem "by mathematical induction or in any other way," she is quite unlikely to consider bypassing the inductive argument.

The important thing to remember is that it is not merely because of the teachers' negligence that situativity of learning is such a widespread phenomenon. Rather, it is the result of the demanding nature of the process of de-ritualization and of our as-yet insufficient acquaintance with this process. In the future, once we have a well-developed theory of de-ritualization, we may be compelled to rethink the way school works.

Open Access This article is distributed under the terms of the Creative Commons Attribution 4.0 International License (http://creativecommons.org/licenses/by/4.0/), which permits unrestricted use, distribution, and reproduction in any medium, provided you give appropriate credit to the original author(s) and the source, provide a link to the Creative Commons license, and indicate if changes were made.

\section{References}

Bell, C. M. (2009). Ritual theory, ritual practice. Oxford: Oxford.

Brown, J. S., Collins, A., \& Duguid, P. (1989). Situated cognition and the culture of learning. Educational Researcher, 18(1), 32-42.

Bruner, J. (1985). Vygotsky: a historical and conceptual perspective. In J. Wertsch (Ed.), Culture, communication and cognition: Vygotskian perspectives (pp. 22-34). Cambridge: Cambridge University Press.

Etzioni, A., \& Bloom, J. (2004). We are what we celebrate: Understanding holidays and rituals. New York: New York University Press.

Feldman, M. S., \& Pentland, B. T. (2003). Reconceptualizing organizational routines as a source of flexibility and change. Administrative Science Quarterly, 48, 94-118.

Feldman, M. S., Pentland, B. T., D’Adderio, L., \& Lazaric, N. (2016). Beyond routines as things: Introduction to the special issue on routine dynamics. Organization Science, 27(3), 505-513.

Geertz, C. (1973). The interpretation of cultures. New York: Basic Books.

Goffman, E. (1959). The presentation of self in everyday life. London: Pinguin Books.

Goffman, E. (1967). Interaction ritual: Essays on face-to-face behavior. New York: Anchor Books.

Greeno, J. G. (1997). On claims that answer the wrong question. Educational Researcher, 26(1), 5-17.

Horn, I. S., \& Little-Warren, J. (2010). Attending to problems of practice: Routines and resources for professional learning in teachers' workplace interactions. American Educational Research Journal, 47(1), 181-121.

Islam, G., \& Zyphur, M. J. (2009). Rituals in organizations: A review and expansion of current theory. Group and Organization Management, 34(1), 114-139.

Jonte-Pace, D. (2009). Foreword: Notes on a friendship. In C. M. Bell, Ritual Theory, Ritual Practice (pp. xii-x). Oxford, UK: Oxford.

Khazemi, E., Lampert, M., \& Ghousseini, H. (2007). Conceptualizing and using routines of practice in mathematics teaching to advance professional education. Paper presented at the Conceptualizing and Using Routines of Practice in Mathematics Teaching to Advance Professional Education, Ann Arbor, Michigan.

Latour, B. (1986). The powers of association. In J. Law (Ed.), Power, action and belief (p. 20). London: Routledge and Kegan Paul.

Lave, J. (1988). Cognition in practice. New York: Cambridge University Press.

Lave, J. (1999). Cognition in practice: Mind, mathematics and culture in everyday life. Cambridge: Cambridge University Press.

Lavie, I., \& Sfard, A. (2016). How children individualize numerical routines - Elements of a discursive theory in making (in Hebrew). Studies in Mathematics Education, 4, 22-68. (עיונים בחינוך מתמטי)

Sfard, A. (1998). Two metaphors for learning and the dangers of choosing just one. Educational Researcher, 27(2), 4-13.

Sfard, A. (2008). Thinking as communicating: Human development, the growth of discourses, and mathematizing. Cambridge: Cambridge University Press.

Sfard, A. (2015). Creating numbers: Participationist discourse on mathematics learning. In D. Butlen, I. Bloch, M. Bosch, C. Chambris, G. Cirade, S. Clivaz, S. Gobert, C. Hache, M. Hersant, \& C. Mangiante. (Eds.), Rôles et 
places de la didactique et des didacticiens des mathématiques dans la société et dans le système éducatif. 17è école d'été de didactique des mathématiques. Nantes du 19 au 26 août 2013 (pp. 79-98). Grenoble: La pensée sauvage.

Sfard, A. (2017). Ritual for ritual, exploration for exploration or what the learners get is what you get from them in return. In J. Adler \& A. Sfard (Eds.), Research for educational change: Transforming researchers' insights into improvement in mathematics teaching and learning (pp. 39-63). London: Routledge.

Sfard, A., \& Lavie, I. (2005). Why cannot children see as the same what grown-ups cannot see as different?Early numerical thinking revisited. Cognition and Instruction, 23(2), 237-309.

Staal, F. (1975). The meaninglessness of ritual. Numen, 26(1), 2-22.

Star, S. L. (2010). This is not a boundary object: Reflections on the origin of a concept. Science, Technology \& Human Values, 35 (5), 601-617. https://doi.org/10.1177/0162243910377624.

Tomasello, M. (2014). A natural history of human thinking. Cambridge: Harvard University Press.

Vygotsky, L. S. (1978). Mind in society: The development of higher psychological processes. Cambridge: Harvard University Press.

Vygotsky, L. S. (1987). Thinking and speech. In R. W. Rieber \& A. C. Carton (Eds.), The collected works of L. S. Vygotsky (pp. 39-285). New York: Plenum Press.

Wittgenstein, L. (1953/2003). Philosophical investigations: The German text, with a revised English translation (G. E. M. Anscombe, Trans) (3rd ed.). Malden: Blackwell Publishing. 